\title{
Contractile Elements and Myosin Light Chain Phosphorylation in Myometrial Tissue from Nonpregnant and Pregnant Women
}

\author{
R. Ann Word, James T. Stull, M. Linette Casey, and Kristine E. Kamm \\ The Cecil H. and Ida Green Center for Reproductive Biology Sciences and the Departments of Obstetrics-Gynecology, \\ Physiology, and Biochemistry, The University of Texas Southwestern Medical Center, Dallas, Texas 75235-9032
}

\begin{abstract}
Smooth muscle contraction is initiated primarily by an increase in intracellular $\mathrm{Ca}^{2+}, \mathrm{Ca}^{2+}$-dependent activation of myosin light chain kinase, and phosphorylation of myosin light chain. In this investigation, we identified pregnancy-associated alterations in myosin light chain phosphorylation, force of contraction, and content of contractile proteins in human myometrium. Steady-state levels of myosin light chain phosphorylation and contractile stress were correlated positively in both tissues, but the myometrial strips from pregnant women developed more stress at any given level of myosin light chain phosphorylation. During spontaneous contractions and during conditions that favor maximal generation of stress, the rate and extent of myosin light chain phosphorylation were attenuated in myometrial strips from pregnant women. The content of myosin and actin per milligram of protein and per tissue cross-sectional area was similar between myometrium of nonpregnant and pregnant women. Although cell size was significantly increased in tissues obtained from pregnant women, the amounts of contractile proteins per cellular cross-sectional area were similar. In addition, myosin light chain kinase and phosphatase activities were similar in the two tissues. The content of caldesmon was significantly increased in myometrium of pregnant women, whereas that of calponin (a smooth muscle-specific protein associated with the thin filaments) was not different. We conclude that adaptations of human myometrium during pregnancy include (a) cellular mechanisms that preclude the development of high levels of myosin light chain phosphorylation during contraction and $(b)$ an increase in the stress generating capacity for any given level of myosin light chain phosphorylation. (J. Clin. Invest. 1993. 92:29-37.) Key words: myometrium • pregnancy • myosin phosphorylation • caldesmon • phosphatase
\end{abstract}

\section{Introduction}

Successful human pregnancy, i.e., a pregnancy ending at term after the spontaneous onset of parturition, encompasses three physiologically and biochemically separable phases of myome-

This work was presented in part at the 38th Annual Meeting of the Society for Gynecologic Investigation, San Antonio, TX, 20-23 March 1991.

Address correspondence to Dr. R. Ann Word, Department of Obstetrics and Gynecology, University of Texas Southwestern Medical Center, 532.3 Harry Hines Blvd., Dallas, TX 75235-9032.

Received for publication 26 October 1992 and in revised form 25 February 1993.

J. Clin. Invest.

(c) The American Society for Clinical Investigation, Inc. 0021-9738/93/07/0029/09 \$2.00

Volume 92, July 1993, 29-37 trial function. The first of these, termed uterine phase 0 of parturition (1), is a state of remarkable uterine quiescence and contractile unresponsiveness, which is maintained for 38 postovulatory weeks. This tranquil state of the uterus persists despite the presence of a "foreign body" distending the endometrial cavity, which leads by virtue of the very rapid growth processes associated with human pregnancy and fetal development, to unparalleled volume expansion of the uterus. In nonpregnant women the uterus readily and spontaneously contracts in response to many perturbations, e.g., the introduction of an intrauterine device into the endometrial cavity, the presence of leiomyomata that impinge into the endometrial cavity, or distentive manipulations of the organ. Yet during pregnancy and the extreme perturbation of the uterus that attends gestation, the myometrium normally remains quiescent. Phase 1 of parturition commences with the suspension of phase 0 and retreat from the maintenance of uterine quiescence (1). During this time there are identifiable morphological and biochemical changes in the uterus; these markers of phase 1 of parturition include cervical ripening/softening and an increase in the number of oxytocin receptors and gap junctions $(2,3)$. These changes are believed to be requisite for the development of forceful, coordinated contractions of active labor, i.e., phase 2 of parturition. After delivery of the conceptus, the period of uterine involution and parturient recovery from childbirth begins, i.e., phase 3 of parturition.

Contraction and relaxation of myometrium (and other smooth muscles) are regulated by phosphorylation and dephosphorylation of the $20-\mathrm{kD}$ light chain of myosin (4-10). Phosphorylation of myosin is effected primarily by an increase in the intracellular concentration of free cytoplasmic $\mathrm{Ca}^{2+}$ $\left(\left[\mathrm{Ca}^{2+}\right]_{i}\right)$. An increase in $\left[\mathrm{Ca}^{2+}\right]_{i}$ results in the activation of myosin light chain kinase (MLCK), ${ }^{1}$ which catalyzes phosphorylation of the regulatory $20-\mathrm{kD}$ light chain subunit of myosin. Phosphorylation of myosin light chain results in actin activation of myosin ATPase activity, the development of force and shortening of the muscle. Relaxation is effected by low $\left[\mathrm{Ca}^{2+}\right]_{\mathrm{i}}$, inactivation of MLCK, and dephosphorylation of myosin light chain by myosin phosphatase. The biochemical adaptations of this cascade that effect myometrial quiescence during pregnancy are undefined as are those that promote the suspension of uterine phase 0 .

This study was conducted as part of an investigation to identify differences in contractile properties (mechanical and biochemical) of myometrium from pregnant and nonpregnant women. In the rat, the stress-generating capacity of the myometrium increases threefold during pregnancy (11). The increased stress-generating capacity required of the myometrium during active labor may be effected by thickening of the uterine wall, increased cell density, increased stress-generating capacity

1. Abbreviation used in this paper: MLCK, myosin light chain kinase. 
of individual smooth muscle cells, or a combination of these factors. We sought to determine if there are pregnancy-associated increases in the stress-generating capacity of human myometrial smooth muscle cells. Also during pregnancy, hypertrophy of human uterine smooth muscle cells is accompanied by increased synthesis of contractile proteins (12), and increases in the myometrial content of calmodulin and myosin light chain kinase have been described during pregnancy in the rabbit (13). Previously, we and others have demonstrated that the contraction/relaxation cycle of myometrial spontaneous contractions is preceded by phosphorylation/dephosphorylation of myosin light chain (14-16). In this investigation we have identified alterations in myosin light chain phosphorylation, force of contraction, and content of contractile proteins in human myometrium during pregnancy. We determined the extent of myosin light chain phosphorylation as a function of time during stimulation of maximal contractile force, and we compared the steady-state relationship between light chain phosphorylation and stress in myometrial tissues from nonpregnant and pregnant women.

\section{Methods}

\section{Source of myometrial tissues}

Normal human myometrial tissue was removed from the uterus of nonpregnant women after hysterectomy for benign gynecologic conditions. In cases of pregnancy, myometrium was either obtained at the time of cesarean-hysterectomy (conducted for reasons of placenta previa $[n=3]$, cervical dysplasia $[n=1]$, placenta accreta $[n=1]$, leiomyoma [ $n=1]$, and elective sterilization [ $n=2]$ ) or from the myometrium of the superior margin of the uterine incision at the time of cesarean section ( not in labor, $n=5$; in labor, $n=4$ ). Informed consent in writing for the use of tissue was obtained from the women undergoing surgery according to a protocol approved by the Institutional Review Board for Human Experimentation at this university. A dissecting microscope was used to discern myometrial bundles from adjacent connective tissue and to identify the orientation of the myometrial fibers.

\section{Contraction of smooth muscle strips}

Strips of human myometrial tissue $(7 \times 1.0 \times 1.0 \mathrm{~mm})$ were stretched to $L_{\mathrm{o}}$ by the application of $12 \mathrm{~g}$ force and conditioned by one contraction in physiologic saline solution that contained $\mathrm{KCl}(65 \mathrm{mM})$ substituted isotonically for $\mathrm{NaCl}$ ( 17). Strips were obtained from the longitudinal layer of the uterine fundus except where indicated. Comparisons of active contractile stress ( force per cross-sectional area) were made at optimal length $L_{\mathrm{o}}$ for maximal force. Cross-sectional area (square centimeters) of each tissue was determined by the formula: $W / L \cdot D$, where $W=$ wet weight of tissue in grams, $L=$ stretched length in centimeters, and $D=$ tissue density $\left(1.05 \mathrm{~g} / \mathrm{cm}^{3}\right)$.

\section{Histology}

To determine the relative amount of smooth muscle cells in the myometrial tissues, strips of myometrium were stretched to $L_{\mathrm{o}}$ and fixed by immersion for $2 \mathrm{~h}$ in sodium phosphate buffer $(\mathrm{pH} 7.2)$ that contained glutaraldehyde $(2 \%, \mathrm{vol} / \mathrm{vol})$. Thereafter, the tissues were fixed in $1 \%$ $\mathrm{OsO}_{4}$, dehydrated, and embedded in Epon. Thick sections (1-3 $\left.\mu \mathrm{m}\right)$ were cut perpendicular to the long axis of the strip at 2-mm intervals (an average of three thick sections per strip). Ultrathin sections (600$900 \AA$ ) were obtained at each interval for electron microscopy and three nonoverlapping photo-micrographs per section (magnified 1,000 times) were analyzed. Total areas analyzed varied from 54,000 to $90,000 \mu \mathrm{m}^{2}$ for different strips. The cellular area was quantified by computerized video analysis (Jandel Scientific, Corte Madera, CA) and expressed as a fraction of the total area in cross-section. Although technique artifacts such as tissue shrinkage may alter the extent of the extracellular space, identical handling of the different tissues permits valid comparisons.

\section{Myosin light chain phosphorylation}

Phosphorylation of myosin light chain was assessed by immunoblot analysis after separation of the non-, mono-, and diphosphorylated forms of myosin light chain by urea/glycerol-PAGE (18). Phosphorylation of myosin light chain was quantified by laser densitometry of the immunoblots with a model 2202 Ultrascan laser densitometer and a model 2220 recording integrator (Pharmacia LKB Biotechnology Inc., Piscataway, NJ) (18). Myosin light chain phosphorylation is expressed as the percent of total $20-\mathrm{kD}$ light chain.

\section{Quantification of contractile proteins}

Myosin light chain kinase activity. The specific activity of myosin light chain kinase was determined in uterine smooth muscle homogenates as described previously with minor modification (19). Briefly, frozen tissues were homogenized in ice-cold buffer $(100 \times$, wt/vol $)$ that contained $100 \mathrm{mM}$ sodium pyrophosphate, $5 \mathrm{mM}$ Tris- $\mathrm{HCl}, 100 \mathrm{mM}$ $\mathrm{NaF}, 50 \mathrm{mM} \mathrm{NaCl}, 5 \mathrm{mM}$ EDTA, $0.1 \%$, wt/ vol NP-40, and $0.1 \mathrm{mM}$ phenylmethylsulfonyl fluoride, $\mathrm{pH}$ 8.0. Thereafter, homogenates were diluted in a reaction mixture (1:5,000 final tissue dilution) that contained $50 \mathrm{mM}$ MOPS, $10 \mathrm{mM}$ magnesium acetate, $1 \mathrm{mM}$ dithiothreitol, $0.4 \mu \mathrm{M}$ calmodulin, $26 \mu \mathrm{M}$ cardiac myosin light chain, and $100 \mu \mathrm{M}$ EGTA-buffered $\mathrm{Ca}^{2+}$. The reaction was initiated with the addition of [ $\left.\gamma-{ }^{32} \mathrm{P}\right]$ ATP $(200-400 \mathrm{cpm} / \mathrm{pmol})$ and terminated by spotting $20-\mu \mathrm{l}$ aliquots of the mixture onto phosphocellulose paper which was then immersed in phosphoric acid. Activities in the presence of EGTA (15 $\mathrm{mM}$ ) served as blanks for the reaction.

Myosin light chain phosphatase activity. Tissues were homogenized in $\operatorname{buffer}(2.5 \times, \mathrm{wt} / \mathrm{vol})$ that contained $100 \mathrm{mM} \mathrm{KCl}, 1 \mathrm{mM} \mathrm{MgCl}, 1$ $\mathrm{mM}$ EGTA, $1 \mathrm{mM}$ dithiothreitol, $20 \mathrm{mM}$ imidazole, $0.1 \mathrm{mM}$ phenylmethylsulfonyl fluoride, and $1 \mu \mathrm{M}$ leupeptin, $\mathrm{pH}$ 7.4. Myosin and myosin light chain were prepared and phosphorylated by smooth muscle MLCK with $\left[\gamma-{ }^{32} \mathrm{P}\right]$ ATP and dialyzed. Phosphorylated light chain and myosin were subjected to SDS-PAGE and autoradiography; ${ }^{32} \mathrm{P}$ was incorporated only in the light chain moiety. Protein phosphatase activity was determined by the release of ${ }^{32} \mathrm{P}_{\mathrm{i}}$ from labeled protein after 1 min incubation at $30^{\circ} \mathrm{C}$ in a reaction mixture that contained $100 \mathrm{mM}$ $\mathrm{KCl}, 1 \mathrm{mM} \mathrm{MgCl} 2,1 \mathrm{mM}$ EGTA, $1 \mathrm{mM}$ ATP, $1 \mathrm{mM}$ dithiothreitol, 10 $\mathrm{mM}$ imidazole, $\mathrm{pH} 7.4$, and $2 \mu \mathrm{M}$ phosphorylated myosin light chain or phosphorylated myosin.

Immunoblot analysis of MLCK and calponin. Proteins in tissue extracts were separated by electrophoresis on SDS-polyacrylamide gels (7\% for MLCK and caldesmon; 12\% for calponin). Proteins were transferred to nitrocellulose at $90 \mathrm{~mA}$ for $14-16 \mathrm{~h}$ in the presence of methanol (20\%) and SDS (0.1\%). Blots were treated with TBST ( 10 $\mathrm{mM}$ Tris, $150 \mathrm{mM} \mathrm{NaCl}, 0.05 \%$ Tween-20) that contained gelatin ( $2 \%$, $\mathrm{wt} / \mathrm{vol}$ ) for $1 \mathrm{~h}$ and then incubated for $4 \mathrm{~h}$ with TBST-gelatin that contained a polyclonal antibody against bovine tracheal MLCK preabsorbed with chicken gizzard caldesmon $(1: 10,000$, vol/vol $)$ or a polyclonal antibody against chicken gizzard calponin $(1: 5,000)$. Thereafter the blots were washed three times with TBST ( 5 min each) and incubated with goat anti-rabbit IgG conjugated with horseradish peroxidase $(1: 20,000)$. After extensive washing with TBST, the blots were developed with a chemiluminescent detection system (ECL Western blotting detection system; Amersham Corp., Arlington Heights, IL). In some cases, the concentration of primary antibody was $1: 1,000$ and the secondary antibody was goat anti-rabbit IgG conjugated with alkaline phosphatase ( $1: 1,000$ for $2 \mathrm{~h}$ ). After three rinses with TBST, phosphatase substrate ( $p$-nitrobluetetrazolium chloride $[0.3 \mathrm{mg} / \mathrm{ml}]$ and $5-$ bromo-4-chloro-3'-indolylphosphate toluidine salt $[0.15 \mathrm{mg} / \mathrm{ml}]$ in carbonate- $\mathrm{Mg}^{2+}$ buffer, $\mathrm{pH} 9.8$ ) was added. The reaction was terminated by extensive washing with deionized $\mathrm{H}_{2} \mathrm{O}$. Densitometry of immunoreactive bands was conducted with a model 2202 ultrascan laser densitometer (Pharmacia LKB Biotechnology Inc.), and compared with a standard curve (on the same blots) constructed by plotting the densitometry values against various amounts of purified proteins. 


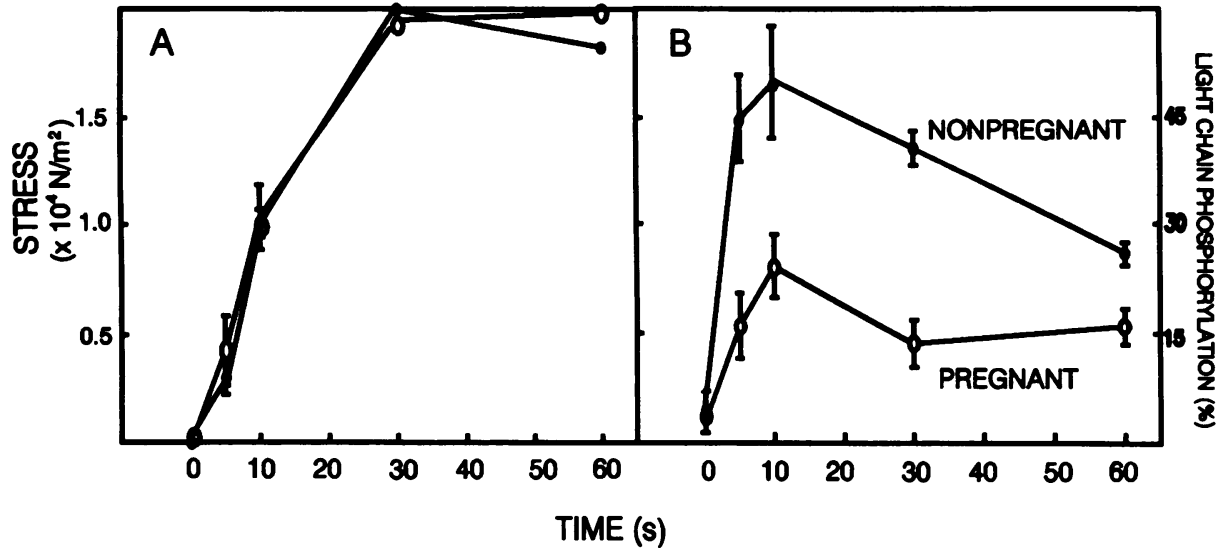

Figure 1. Myosin light chain phosphorylation-stress relationship during maximal contractile stimulation. $(A)$ Generation of isometric stress is plotted as a function of time. $(B)$ Myosin light chain phosphorylation is expressed as the percent of total immunoreactive light chain that is phosphorylated. Each point represents the mean \pm SEM for four to eight samples obtained from seven nonpregnant (open circles) and five pregnant women before the onset of labor (closed circles). Data from pregnant women were obtained from the longitudinal layer of the uterine fundus after cesarean-hysterectomy.
Immunoblot analysis of calmodulin. Proteins in tissue extracts were separated by electrophoresis on urea-glycerol polyacrylamide (10\%) gels exactly as described for determination of myosin light chain phosphorylation (17). After transfer to nitrocellulose, the blot was incubated for 3-4 h with a monoclonal antibody $(10 \mu \mathrm{g} / \mathrm{ml})$ raised to calmodulin. Immunoreactive calmodulin was visualized by use of goat anti-mouse $\mathrm{IgG}$ conjugated to alkaline phosphatase and phosphatase substrates as for caldesmon. Comparison of the areas of immunoreactive bands was conducted by laser densitometry.

Protein and DNA analyses

Total protein was determined by the method of Lowry et al. (20) and DNA was determined by the method of Burton (21).

\section{Materials}

Endothelin-1 was purchased from Peptides Intl. Inc. (Louisville, KY). $\left[\gamma-{ }^{32} \mathrm{P}\right]$ ATP was obtained from ICN Biomedicals, Inc. (Irvine, CA). Calyculin-A was obtained from LC Laboratories (Woburn, MA) and okadaic acid from Calbiochem Corp. (La Jolla, CA). Affinity-purified, anti-calponin polyclonal antibody ( raised against avian gizzard smooth muscle calponin; $35 \mathrm{kD}$ ) and purified calponin were obtained from Dr. Michael Walsh (University of Calgary, Calgary, Alberta, Canada).

\section{Results}

Stress-generating capacity and myosin light chain phosphorylation-stress relationship. Maximal stress-generating capacity of intact myometrial strips was determined at optimal length by treatment with physiologic salt solution that contained 100 $\mathrm{mM} \mathrm{KCl}, 5 \mathrm{mM} \mathrm{Ca}^{2+}$, and $10^{-8} \mathrm{M}$ endothelin-1. Maximal stress responses of myometrium from nonpregnant women were similar to those of pregnant women $(1.81 \pm 0.12 \mathrm{com}$ pared with $1.90 \pm 0.13 \times 10^{4} \mathrm{~N} / \mathrm{m}^{2}$ for myometrium of pregnant women; Fig. $1 \mathrm{~A}$ ). Myosin light chain phosphorylation increased from 4 to $50 \%$ in $5 \mathrm{~s}$ after maximal stimulation and then decreased to $41 \%$ by $30 \mathrm{~s}$ (Fig. $1 \mathrm{~B}$ ). Although similar levels of stress developed, the rate and extent of light chain phosphorylation were significantly diminished in the strips from pregnant women (Fig. $1 B$ ). At $30 \mathrm{~s}$ (near-maximal stress development), light chain phosphorylation was $41 \pm 1.4 \%$ in myometrium from nonpregnant women and $14 \pm 1.2 \%$ in myometrium from pregnant women $(P<0.01)$. Likewise, stimulation of myometrial tissues from pregnant women in labor resulted in low levels of light chain phosphorylation (data not shown). Thus, even during conditions that favor maximal generation of contractile force, the extent of myosin light chain phosphorylation in myometrial tissues from pregnant women was very low.
Steady-state levels of myosin light chain phosphorylation and stress generation were determined after treatment with calyculin-A, an inhibitor of types 1 and 2 protein phosphatases. Treatment of myometrial strips with various concentrations of calyculin-A resulted in the rapid onset of a phasic contraction that was of greater force amplitude than antecedent spontaneous contractions. Thereafter, steady-state levels of active force increased with a marked decrease in the frequency of spontaneous contractions. The muscle was frozen after $45 \mathrm{~min}$. The amount of steady-state stress generated by myometrial tissues from pregnant women was greater at any given level of light chain phosphorylation than that of nonpregnant women. For example, the amount of contractile force at $15 \%$ light chain phosphorylation in myometrium of pregnant women was similar to that achieved at levels of $40 \%$ light chain phosphorylation in myometrium from nonpregnant women (Fig. 2). The

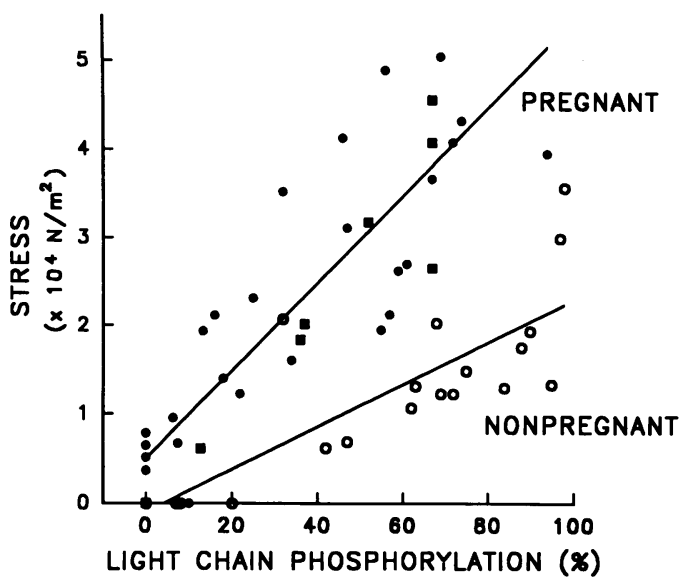

Figure 2. Relationship between the steady-state levels of myosin light chain phosphorylation and stress in uterine smooth muscle. Steadystate levels of isometric force were obtained by treatment with calyculin-A at various concentrations $\left(1 \times 10^{-8}-2 \times 10^{-6} \mathrm{M}\right)$. After 45 $\mathrm{min}$, strips of uterine smooth muscle tissue were frozen and prepared for qualification of myosin light chain phosphorylation. Each point is representative of data obtained from 20 strips from 6 uteri of nonpregnant women (open circles) and 36 strips from 9 uteri of pregnant women (closed symbols; circles are from women not in labor; squares are from women in labor). There is a positive correlation between light chain phosphorylation and stress in myometrial tissue from nonpregnant ( $r=0.777, P<0.001)$ and pregnant women $(r=0.85$, $P<0.001)$. The slope of the regression line of data from pregnant women was 2.2-fold greater than that from nonpregnant women. 
stress/light chain phosphorylation ratio was 2.2-fold greater in myometrium from pregnant women (i.e., the difference between the slopes of the two regression lines). There was no difference in the stress-phosphorylation relationship between tissues obtained before or after the onset of active labor (Fig. 2 ). Responsiveness to oxytocin and $\mathrm{KCl}$ was similar in myometrium obtained from the lower uterine segment and in that obtained from the uterine fundus. Moreover, the steady-state myosin light chain phosphorylation-stress relationship was similar in tissues from the two sites (data not shown). These data demonstrate that the stress generation capacity relative to myosin light chain phosphorylation is significantly increased with pregnancy. The reasons for this adaptation were explored further.

Histologic analysis. We sought to determine if the increased myosin light chain phosphorylation-stress relationship in myometrial tissue during pregnancy resulted from an increase in the fraction of cross-section occupied by smooth muscle cells. To do so, we analyzed cross-sections of smooth muscle strips from nonpregnant and pregnant women and computed the fraction of cross-sectional area occupied by bundles of smooth muscle cells ( Table I). The fraction of myometrial cells that were oriented perpendicular to the strip axis was $85-90 \%$ in both tissue preparations. Whereas the fraction of total tissue cross-sectional area occupied by smooth muscle cells was similar in the two tissues, the number of nuclei per cross-sectional area was decreased four- to fivefold in the myometrium of pregnant women. Thus, although cellular size was increased in myometrial tissues obtained from pregnant women, cellular content per tissue cellular cross-sectional area was similar.

Tissue content of actin and myosin. Myosin and actin contents (expressed as micrograms per milligram of total protein) was quantified after SDS-PAGE (3-20\% acrylamide gradient, Table II). The amount of muscle extract (20-40 $\mu \mathrm{g})$ was linear with the areas of the investigated proteins on the densitometric scans. Whereas the amounts of actin and myosin per milligram protein, or per gram wet weight, were similar in tissues obtained from nonpregnant and pregnant women, there was a fourfold increase in the amounts of these proteins when expressed per microgram DNA (Table II). Thus, although the content of actin and myosin per myocyte is increased during pregnancy, the amount of contractile protein per milligram protein is not different between the two tissues. In addition, there were no differences in tissue protein content.

Thin filament-associated proteins: caldesmon and calponin. The concentration of thin filament proteins in myometrial tissue from nonpregnant and pregnant women was determined by immunoblot analysis. We found that uterine tissues contain both low (1) and high ( $h$ ) molecular weight isoforms of immunoreactive caldesmon, the high molecular form being in

Table I. Histologic Analysis of Myometrial Tissue Strips

\begin{tabular}{lcc}
\hline & Nonpregnant & Pregnant \\
\hline Cellular fraction, \% & $62.0 \pm 5.4$ & $65.0 \pm 4.4$ \\
Nuclei/mm m $^{2}$ & $3,444 \pm 934$ & $728 \pm 106^{*}$
\end{tabular}

Data are mean \pm SEM of 9-15 cross-sections from strips of myometrial tissue at $L_{\mathrm{o}}$ from nonpregnant $(n=4)$ and pregnant $(n=3)$ women. ${ }^{*} P<0.05$.
Table II. Tissue Amounts of Total Protein, DNA, Myosin, and Actin in Myometrium of Nonpregnant and Pregnant Women

\begin{tabular}{lcc}
\hline & Nonpregnant $(n=11)$ & Pregnant $(n=15)$ \\
\hline $\begin{array}{l}\text { Total protein } \\
\mu \mathrm{g} / \mathrm{mg} \text { wet wt }\end{array}$ & $53.6 \pm 0.63$ & \\
$\mathrm{DNA}$ & & $51.1 \pm 2.20$ \\
$\mu \mathrm{g} / \mathrm{mg}$ protein & $66.8 \pm 8.0$ & \\
$\mathrm{Myosin^{ \ddagger }}$ & & $13.5 \pm 1.7^{*}$ \\
$\mu \mathrm{g} / \mathrm{mg}^{*}$ protein & $46.1 \pm 5.59$ & \\
$\mathrm{mg} / \mathrm{g}$ wet wt & $2.2 \pm 0.23$ & $54.3 \pm 3.93$ \\
$\mu \mathrm{g} / \mu \mathrm{g}$ DNA & $0.60 \pm 0.10$ & $2.8 \pm 0.22$ \\
$\mathrm{Actin}$ & & $2.45 \pm 0.29^{*}$ \\
$\mu \mathrm{g} / \mathrm{mg}$ protein & $300.6 \pm 16.5$ & $320.2 \pm 13.2$ \\
$\mathrm{mg} / \mathrm{g}$ wet $\mathrm{wt}$ & $15.2 \pm 0.83$ & $16.5 \pm 0.62$ \\
$\mu \mathrm{g} / \mu \mathrm{g}$ DNA & $5.25 \pm 1.20$ & $22.3 \pm 2.29^{*}$ \\
\hline
\end{tabular}

$* P<0.01$.

‡ Calculated by multiplying the myosin heavy chain estimates by 1.19 to correct for light chains.

greatest abundance. The amounts of immunoreactive caldesmon $\mathrm{h}$ in uterine smooth muscle of pregnant women expressed per milligram tissue protein were increased fourfold as compared with those of nonpregnant women (Fig. 3). This increase in immunoreactivity in myometrium of pregnant women represents a 20 -fold increase in caldesmon content per microgram DNA. The accuracy of the quantification of the amount of caldesmon by comparing immunoreactivity of human caldesmon with standard amounts of caldesmon from avian gizzard smooth muscle is not known (because the polyclonal antibody was raised to chicken gizzard caldesmon); however, with the exception of the rat, the cloned mammalian caldesmons are very similar (77-85\% identity) to the chicken gizzard isoforms. We can conclude that the relative amounts of immunoreactive caldesmon in human myometrium are increased four- to fivefold during pregnancy.

The content of calponin, another actin-binding (thin filament) protein that is specific for smooth muscle, was not increased in myometrium from pregnant women. By immunoblot analysis with a polyclonal antibody against chicken gizzard calponin, we identified two immunoreactive proteins ( 23 and $40 \mathrm{kD}$ ) in homogenates of all samples of myometrium (from pregnant and nonpregnant women; Fig. $3 \mathrm{~B}$ ). The structural/functional differences between these immunoreactive protein forms are not known. Inclusion of protease inhibitors in the homogenates did not alter the immunoblot pattern, and preabsorption of the anti-calponin antibody with purified calponin markedly reduced the immunoreactivity of both molecular weight species. A single immunoreactive band was found in tissue homogenates from chicken gizzard. Thus it is possible that human myometrium contains two distinct isoforms of calponin that are similar to those in bovine platelets (22). We found no differences in the content of calponin of either size in homogenates of uterine smooth muscle from nonpregnant and pregnant women (Fig. $3 \mathrm{D}$ ).

Tissue contents of $M L C K$, myosin light chain phosphatase, and calmodulin. The second striking pregnancy-induced alteration in myometrium is the diminished biochemical response to stimulation as reflected by very low levels of myosin light 
A CALDESMON

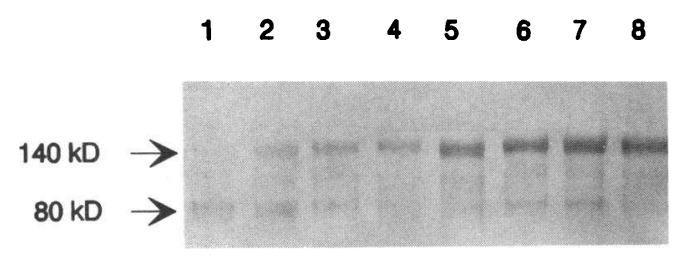

B

CALPONIN

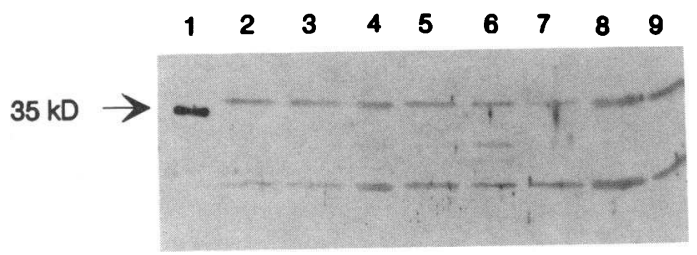

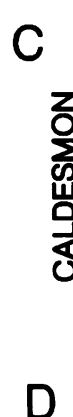
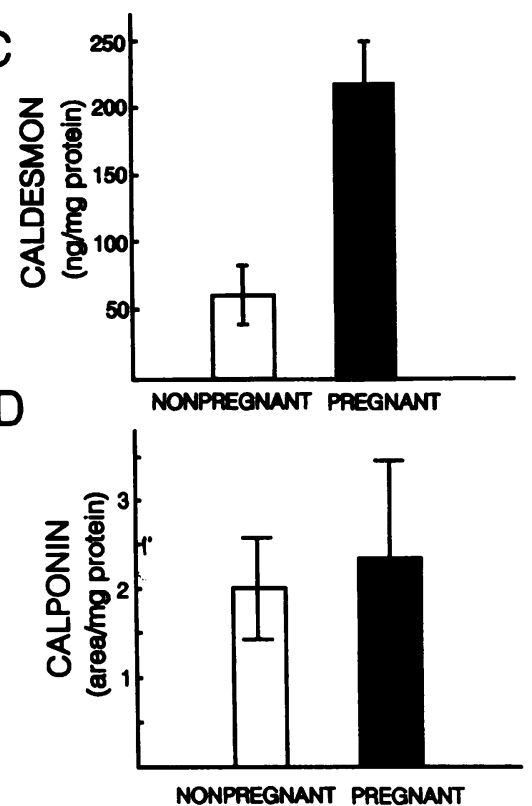

Figure 3. Immunoreactive caldesmon (top) and calponin (bottom) in myometrial homogenates from nonpregnant and pregnant women. ( $A$ ) Immunoreactive caldesmon $\mathrm{h}$ $(145 \mathrm{kD})$ and $1(80 \mathrm{kD})$ are visualized in lanes $1-4$ (from nonpregnant women) and lanes 5-8 (pregnant women $)$. Tissue proteins $(20 \mu \mathrm{g})$ were applied in each lane. Caldesmon content was quantified by standard curves with various concentrations of purified caldesmon (chicken gizzard) and immunoblot analysis of six tissues from nonpregnant and six tissues from pregnant women $(C)$. (B) Immunoreactive calponin in lanes 2-5 from myometrial homogenates of nonpregnant women; lanes 6-9 from pregnant women. Calponin purified from avian gizzard is presented as the standard (lane 1$)$. (D) Densitometric analysis of total amounts of immunoreactive calponin from nonpregnant and pregnant women expressed per total protein applied to the gel. chain phosphorylation during contraction. Therefore, the possibility that this physiological change could be due to specific alterations in the levels of expression of regulatory proteins (MLCK, myosin light chain phosphatase, and calmodulin) was investigated. The total specific activity of MLCK in whole homogenates of uterine smooth muscle tissues from myome- trium of nonpregnant women was not different from that of myometrium of pregnant women (Fig. $4 \mathrm{~A}$ ). Furthermore, MLCK activity was $\mathrm{Ca}^{2+} /$ calmodulin dependent. As in the case of actin and myosin, the activity of MLCK per microgram of DNA was increased in uterine tissue from pregnant women (Fig. $4 \mathrm{~B}$ ). Thus, although the amount of MLCK per myocyte
A

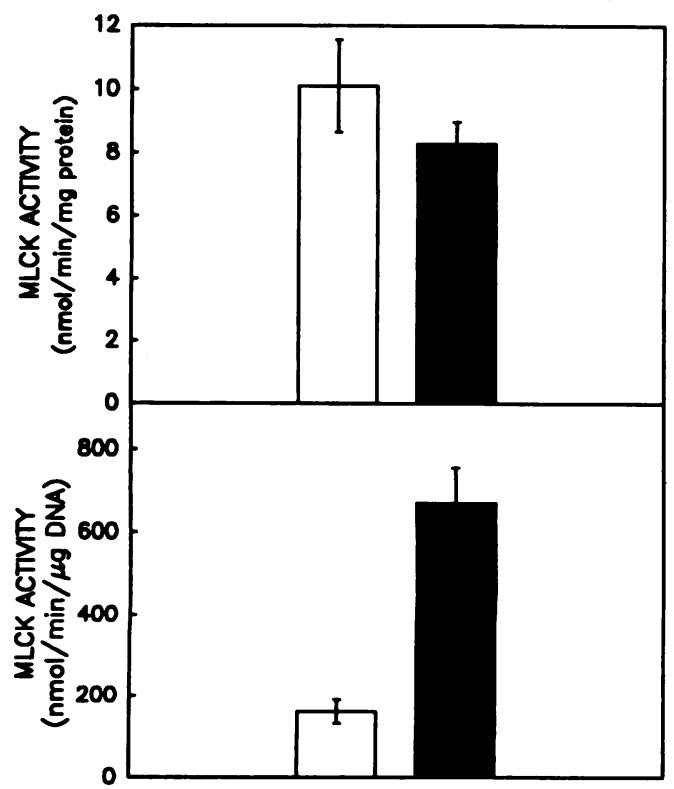

B

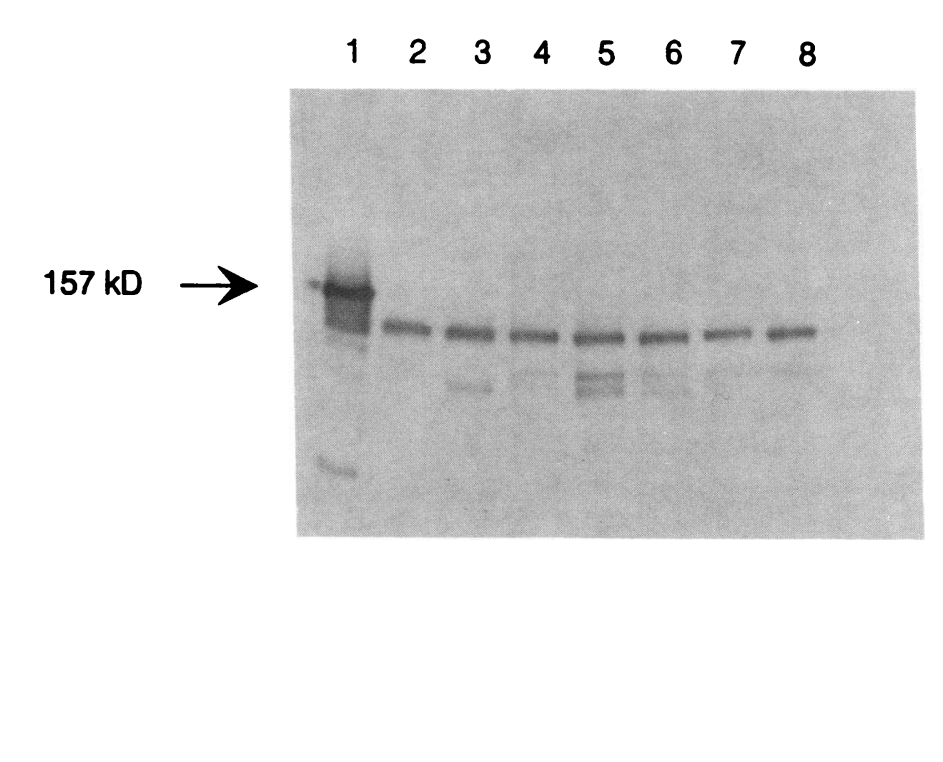

Figure 4. Effect of pregnancy on MLCK activity in human myometrium. $(A)$ Data are expressed as nanomoles ${ }^{32} \mathrm{P}$ incorporated per minute per milligram protein or micrograms DNA in homogenates of myometrial tissue from nonpregnant (open bar) and pregnant (solid bar) women. $(B)$ Immunoblot analysis of MLCK in human myometrium ( $10 \mu \mathrm{g}$ total protein). Lane 1 , purified MLCK from bovine trachealis; lanes 2-4, myometrium from nonpregnant women; lanes 5-8, myometrium from pregnant women. 
is increased during pregnancy, the specific activity of MLCK expressed per milligram of protein is not different between the two tissues. By immunoblot analysis, the amount of immunoreactive MLCK (per milligram protein) was also similar in the two tissues (Fig. 4). The apparent estimate of molecular mass by SDS-PAGE from human myometrium (and other human smooth muscle tissues such as uterine artery and fetal aorta; data not shown) is less than that reported for rabbit or bovine MLCKs ( 137 compared with 157 kD for bovine MLCK; Fig. 4). This finding is consistent with the observation that MLCKs from different species exhibit different mobility patterns on SDS gels (23) and is probably related to differences in the amino acid composition of the $\mathrm{NH}_{2}$-terminal tail portion of the enzyme.

Phosphatase activity was determined with both ${ }^{32} \mathrm{P}$-labeled myosin light chain and ${ }^{32} \mathrm{P}$-labeled intact myosin as substrates. We found that the rate of dephosphorylation of isolated myosin light chain is less in uterine homogenates from pregnant women than that from nonpregnant women (Fig. $5 \mathrm{~A}$ ). The dephosphorylation of light chains in the intact myosin molecule, however, was not different between the two tissues (Fig. 5 ). Because myosin light chain is a substrate for protein phosphatases types 1 and 2, we used okadaic acid, a phosphatase inhibitor that is most specific for type 2A protein phosphatase, to characterize further the phosphatase activity in these tissues. In these experiments, a significant amount of light chain dephosphorylation was inhibited by okadaic acid at low concentrations (Fig. $5 \mathrm{~B}$ ). The percent of phosphatase activity that is 2A-like in myometrial tissues is greater than that of a tonic smooth muscle, bovine trachealis; but the relative amounts of activity that are sensitive to okadaic acid at low concentration are similar between the two myometrial tissues (Fig. $5 \mathrm{~B}$ ). Thus, the decreased myosin light chain phosphorylation in uterine smooth muscle from pregnant women is probably not due to increases in the specific activity of type 1 myosin light chain phosphatase.

Calmodulin content was evaluated by immunoblot analysis after urea-glycerol gel electrophoresis. There were no differ-
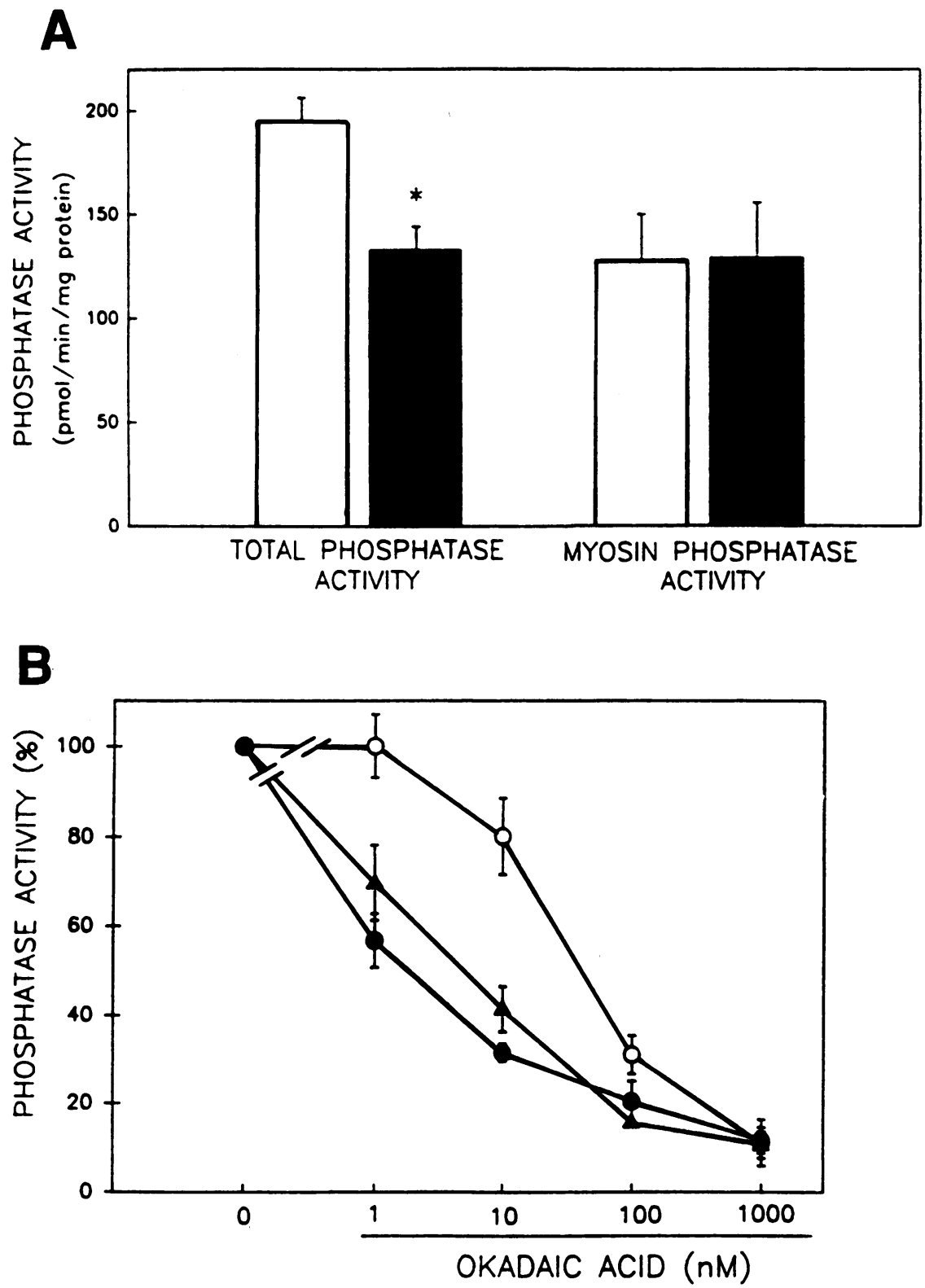

Figure 5. Myosin light chain phosphatase activity in human myometrium. $(A)$ Phosphatase activity in homogenates of myometrium from nonpregnant (open bar) and pregnant (closed bar) women with light chain (total activity) and whole myosin (myosin phosphatase activity) as substrates. $(B)$ Inhibition of total phosphatase activity of myometrial (closed symbols) and tracheal smooth muscle (open circles) homogenates by okadaic acid. Phosphatase activity of myometrial tissues was significantly inhibited by okadaic acid compared with bovine trachealis $\left(\mathrm{EC}_{50}, 9.3 \pm 2.13\right.$ compared with $63.6 \pm 10.3 \mathrm{nM}$ for trachealis, $P<0.01$ ). 
ences in the amounts of immunoreactive calmodulin in myometrium of pregnant or nonpregnant women (data not shown).

\section{Discussion}

Although there have been major advances in our understanding of the regulation and physiological functions of contractile proteins in smooth muscle in recent years (24), very little information exists on the functional status of these proteins in human myometrium during pregnancy. In the bicornuate uterus of the rat, the force-generating capacity triples during pregnancy (11), and, in the rabbit, the content of MLCK and calmodulin increase 2- and 1.4-fold, respectively (13). In this study, we evaluated the relationship between myosin light chain phosphorylation and stress generation in human myometrium during pregnancy. Treatment of myometrial strips with a high concentration of $\mathrm{KCl}$ plus endothelin- 1 in the presence of high extracellular $\left[\mathrm{Ca}^{2+}\right]$ resulted in time-dependent increases in myosin light chain phosphorylation in myometrial tissues from nonpregnant and pregnant women. The extent of myosin light chain phosphorylation, however, was much less in the myometrium of pregnant women. We tested the hypothesis that the force-generating capacity of myometrium during pregnancy is increased provided myosin light chain phosphorylation levels can be increased to higher levels. By use of the phosphatase inhibitor, calyculin-A, we found that the myometrium of pregnant women has the capacity to generate increased levels of stress for any given level of myosin light chain phosphorylation. The stress/myosin light chain phosphorylation ratio was 2.2-fold greater in myometrium from pregnant women near term than in myometrium from nonpregnant women. Taken together, these data suggest that: $(a)$ the myometrium of pregnant women has the capacity to generate greater stress relative to the extent of light chain phosphorylation, and $(b)$ physiologically, pregnancy-associated changes in the myometrial cell (not yet identified) preclude the development of high levels of myosin light chain phosphorylation. These two changes in myometrial contractile properties during pregnancy are distinct but may be functionally related.

We sought to determine if changes in the myosin light chain phosphorylation-stress relationship in myometrium of pregnant women were due to alterations in the content of contractile proteins. We found, as have others $(25)$, that the content of myosin and actin in myometrial tissues from nonpregnant women is not altered during pregnancy. The concentrations of myosin reported herein (determined by densitometric scans from Coomassie-stained SDS-PAGE gels of myometrial homogenates) are similar to those reported by extraction and purification of myosin ( $1.8 \pm 0.14$ for nonpregnant women compared with $2.9 \pm 0.31 \mathrm{mg} / \mathrm{g}$ for pregnant women; 22$)$. Other investigators have reported that the myosin isoform distribution and the myosin ATPase activities are similar between the two tissues (26). Although the content of actin does not change, the expression of the more basic actin isoform in myometrial tissue is enhanced during pregnancy. It has been reported that the apparent affinity of this actin that is extracted from myometrium of pregnant women for myosin subfragment- 1 is higher than that of actin extracted from myometrium of nonpregnant women (27). The significance of this finding is not clear because the actomyosin ATPase $V_{\max }$ from a variety of skeletal and smooth muscle preparations is independent of actin isoforms $(28,29)$. Smooth muscle actomyosin ATPase activity is regulated primarily by the level of myosin light chain phosphorylation $(7,8,10,30)$ and the presence of other regulatory thin-filament proteins (31-34). It is unlikely that the content of actin and myosin or their isoform distributions contribute to the altered myosin light chain phosphorylation-stress relationship observed in human myometrium during pregnancy.

The protein phosphatase that dephosphorylates myosin light chain in vivo has not been clearly established (35-40). Although several phosphoprotein phosphatases that dephosphorylate myosin light chain have been isolated from vascular (41) and nonvascular smooth muscles (40), none manifest complete substrate specificity. Experimental data obtained with protein phosphatase inhibitors okadaic acid (more specific for type 2A; reference 42) and calyculin A (more specific for type 1; reference 43) are supportive of the view that type 1 protein phosphatase is the dominant phosphatase that catalyzes the dephosphorylation of myosin in most muscles. In this investigation, we found that treatment of $\mathrm{Ca}^{2+}$-depleted myometrial tissues with calyculin-A in the absence of extracellular $\mathrm{Ca}^{2+}$ resulted in the development of significant levels of stress and myosin light chain phosphorylation (87\%; data not shown). Thus, myosin phosphatases are important regulators of uterine smooth muscle contractility. In this investigation, serine/threonine phosphatase activity was determined in myometrial homogenates with ${ }^{32} \mathrm{P}$-labeled myosin light chain and ${ }^{32} \mathrm{P}$-labeled whole myosin as substrates. In homogenates of myometrium from pregnant women, phosphatase activity determined using light chain as substrate was lower than that in homogenates of myometrium from nonpregnant women. This phosphatase activity was inhibited by okadaic acid (a phosphatase inhibitor more specific for type 2 phosphatases) at low concentration. The specific activity of phosphatase determined with the intact myosin molecule as substrate, however, was not different between the two tissues. Calyculin- $A$ is inhibitory to types 1, 2A, and 2B, and thus does not serve to distinguish among protein phosphatases. Taken together, we conclude that the altered myosin light chain phosphorylation-stress relationship in uterine smooth muscle from pregnant women is probably not attributable to alterations in the specific activities of MLCK, myosin light chain phosphatase, or calmodulin.

The extent of phosphorylation of smooth muscle myosin is regulated by the relative activities of MLCK and myosin light chain phosphatase. The decreased levels of myosin light chain phosphorylation in myometrium of pregnant women may be due to $(a)$ decreased activation by lower concentrations of free cytoplasmic $\mathrm{Ca}^{2+}$ or to $(b)$ alterations in the activation properties of the enzyme by phosphorylation. Although the content of MLCK was not different between the two tissues, alterations in the activation properties of MLCK during contraction may contribute to different levels of light chain phosphorylation in these smooth muscles. In vitro, MLCK purified from smooth muscle is phosphorylated at a specific serine residue ( site A) by a number of different protein kinases (44-47). Site A phosphorylation results in a decrease in the $\mathrm{Ca}^{2+} /$ calmodulin activation properties of the enzyme. Recently, we have demonstrated that MLCK activity can be modulated in vivo by phosphorylation $(48,49)$ and that the kinase responsible for phosphorylation of MLCK in intact smooth muscle cells is $\mathrm{Ca}^{2+} /$ calmodulin-dependent protein kinase II (49). The possibility of increased phosphorylation of MLCK and its resulting 
decreased activation potential in the myometrium of pregnant women is currently under investigation.

The finding of increased amounts of the thin filament protein, caldesmon, but not calponin, in myometrium of pregnant women is suggestive of specific regulation of this thin-filament protein during pregnancy and the possible importance of this protein in modulation of uterine contractility. Although a role for caldesmon in the regulation of smooth muscle contraction has been suggested $(32,33,50-53)$, there is considerable uncertainty and controversy regarding its regulatory mechanism and physiologic relevance $(54,55)$. Additional experiments will be necessary to determine the significance of the increased caldesmon content in human myometrium during pregnancy.

In this study, the pregnancy-associated enhancement in myometrial cell stress-generating capacity as a function of light chain phosphorylation was present irrespective of the presence or absence of labor. Importantly, in these studies, as well as in those conducted previously (17), we have identified no differences in the frequency, amplitude, or duration of spontaneous contractions in myometrium obtained from women before or after the onset of labor. In both cases, stress development of spontaneous contractions was comparable to that seen in myometrial tissues from nonpregnant women but with significantly lower levels of light chain phosphorylation ( see Fig. 1). It is not known if the stress developed by myometrial tissues in vitro is comparable to that during labor in vivo. It is possible that the withdrawal of the factors responsible for the maintenance of uterine quiescence results in spontaneous contractions. The stress of these contractions associated with low levels of myosin light chain phosphorylation may be sufficient to effect delivery of the fetus because uterine mass and wall thickness is increased during pregnancy. In addition, the extent of light chain phosphorylation may be greater in vivo so that the muscle manifests its full stress-generating capacity. Thus, other factors may be important in effecting the transition from phase 1 to phase 2 of parturition; namely, a uterotonin may be required to effect further increases in $\left[\mathrm{Ca}^{2+}\right]_{i}$, myosin light chain phosphorylation, and contractile force.

This is the first report of adaptations in the myosin light chain phosphorylation-stress relationship in any smooth muscle under different physiologic conditions. During pregnancy, human myometrium is more sensitive to the effects of myosin light chain phosphorylation with no appreciable increases in the content of actin and myosin. Although increases in the content of caldesmon may be related to this increased sensitivity to light chain phosphorylation, additional investigations are necessary to test this hypothesis. Increases in stress generation for a given amount of contractile material may be achieved by way of intercellular communication through gap junctions between adjacent myometrial smooth muscle cells $(3,56)$. It has been demonstrated, however, that in skinned fibers where all cells are exposed to increased free cytoplasmic $\mathrm{Ca}^{2+}$, fibers from pregnant women develop greater levels of force than those from nonpregnant women (57). Thus, the spread of excitation or coupling of adjacent myocytes does not appear to provide an additional mechanical advantage. Effective coordination of myometrial contraction may be facilitated by gap junctions, the number and size of which increase during phase 1 before the commencement of phase 2 of parturition (3). Other cytostructural alterations in the hypertrophied myocytes of pregnant women may contribute to an increase in stress generation by this tissue (58), and the increased content in caldesmon in myometrium of pregnant women may facilitate these adaptations of the myometrial cell during pregnancy.

\section{Acknowledgments}

We thank Leah Hamilton, R.N., and Valencia Hoffman for assistance in obtaining tissues, and Hal Schofield and Sema Fofung for skilled technical assistance.

This investigation was supported in part by National Institutes of Health grants HD-11149 and HD-26164, and March of Dimes Birth Defects Foundation grant 6-584. Dr. Word was a physician-scientist fellow supported in part by the American Association of Obstetricians and Gynecologists Foundation of the American Gynecological Society.

\section{References}

1. Casey, M. L., and P. C. MacDonald. 1992. Human parturition: prostaglandins and cytokines are sequelae of labor. Proceedings of the 9th International Congress on Endocrinology. Nice, France. Parthenon Publishing Group, Carnforth, UK. In press.

2. Soloff, M. S., M. Alexandrova, and M. J. Ferström. 1979. Oxytocin receptors: triggers for parturition and lactation? Science (Wash. DC). 204:1313-1315

3. Garfield, R. E., M. G. Blennerhassett, and S. M. Miller. 1988. Control of myometrial contractibility: role and regulation of gap junctions. $O x f$. Rev. $R e-$ prod. Biol. 10:436-490.

4. Haeberle, J. R., D. R. Hathaway, and A. A. DePaoli-Roach. 1985. Dephosphorylation of myosin by the catalytic subunit of a type-2 phosphatase produces relaxation of chemically skinned uterine smooth muscle. J. Biol. Chem. 260:9965-9968.

5. Haeberle, J. R., J. W. Hott, and D. R. Hathaway. 1985. Regulation of isometric force and isotonic shortening velocity by phosphorylation of the 20,000 dalton myosin light chain of rat uterine smooth muscle. Pflügers Arch. Eur. J. Physiol. 403:215-219.

6. Csabina, S., V. Mougios, M. Barany, and K. Barany. 1986. Characterization of the phosphorylatable myosin light chain in rat uterus. Biochim. Biophys. Acta. 871:311-315.

7. Hai, C.-M., and R. A. Murphy. 1989. $\mathrm{Ca}^{2+}$, crossbridge phosphorylation, and contraction. Annu. Rev. Physiol. 51:285-298.

8. Kamm, K. E., and J. T. Stull. 1985. The function of myosin and myosin light chain kinase phosphorylation in smooth muscle. Annu. Rev. Pharmacol. Toxicol. 25:593-620.

9. Kamm, K. E., and J. T. Stull. 1989. Regulation of smooth muscle contractile elements by second messengers. Annu. Rev. Physiol. 51:299-313.

10. Kamm, K. E., and J. T. Stull. 1985. Myosin phosphorylation, force, and maximal shortening velocity in neurally stimulated tracheal smooth muscle. $\mathrm{Am}$. J. Physiol. 249:C238-C247.

11. Sparrow, M. P., M. A. Mohammed, A. Arner, P. Hellstrand, and J. C. Rüegg. 1988. Myosin composition and functional properties of smooth muscle from the uterus of pregnant and non-pregnant rats. Pflugers Arch. Eur. J. Physiol. 412:624-633.

12. Dessouky, D. A. 1971. Myometrial changes in postpartum uterine involution. Am. J. Obstet. Gynecol. 110:318-329.

13. Matsui, K., K. Higashi, T. Yoshimura, M. Itoh, and E. Mujamato. 1986. Myosin light chain kinase and cyclic AMP-dependent protein kinase activities and calmodulin levels in placental and non-placental regions of the rabbit myometrium. J. Endocrinol. 109:97-100.

14. Janis, R. A., K. Barany, M. Barany, and J. G. Sarmiento. 1981. Association between myosin light chain phosphorylation and contraction of rat uterine smooth muscle. Mol. Physiol. 1:3-11.

15. Dokhac, L., A. D'Albis, C. Janmot, and S. Harbon. 1986. Myosin light chain phosphorylation in intact rat uterine smooth muscle: role of calcium and cyclic AMP. J. Muscle Res. Cell Motil. 7:259-268.

16. Word, R. A., M. L. Casey, K. E. Kamm, and J. T. Stull. 1991. Effects of CGMP and activators of guanylate cyclase on $\left[\mathrm{Ca}^{2+}\right]_{i}$, myosin light chain phosphorylation, and contraction in human myometrium. Am. J. Physiol. 29:C861C867.

17. Word, R. A., K. E. Kamm, and M. L. Casey. 1992. Contractile effects of prostaglandins, oxytocin, and endothelin in human myometrium in vitro: refractoriness of myometrial tissue of pregnant women to prostaglandins $E_{2}$ and $F_{2 \alpha} . J$. Clin. Endocrinol. Metab. 75:1027-1032.

18. Persechini, A., K. E. Kamm, and J. T. Stull. 1986. Different phosphorylated forms of myosin in contracting tracheal smooth muscle. J. Biol. Chem. 261:6293-6299.

19. Richardson, M. R., D. A. Taylor, M. L. Casey, P. C. MacDonald, and J. T. Stull. 1987. Biochemical markers of contraction in human myometrial smooth muscle cells in culture. In Vitro (Rockville). 23:21-28.

20. Lowry, O. H., N. J. Rosebrough, A. L. Farr, and R. J. Randall. 1951. 
Protein measurement with the Folin phenol reagent. J. Biol. Chem. 193:265275.

21. Burton, K. 1956. A study of the mechanisms of the diphenylamine reaction for the calorimetric estimation of deoxyribonucleic acid. Biochem. $J$. 62:315-322.

22. Takahashi, K., K. Hiwada, and T. Kokubu. 1988. Vascular smooth muscle calponin: a novel troponin T-like protein. Hypertension (Dallas). 11:620626 .

23. Stull, J. T., M. H. Nunnally, and C. H. Michnoff. 1986. In The Enzymes Vol. XVII. E. G. Krebs and P. D. Boyer, editors. Academic Press, Inc., Orlando, FL. 113-166.

24. Huszar, G. 1986. Cellular regulation of myometrial contractility. In The Physiology and Biochemistry of the Uterus in Pregnancy and Labor. G. Huszar, editor. CRC Press, Inc., Boca Raton, FL. 107-126.

25. Cavaillé, F., and J. J. Leger. 1983. Characterization and comparison of the contractile proteins from human gravid and non-gravid myometrium. Gynecol. Obstet. Invest. 16:341-351.

26. Ewoane, C., and F. Cavaille. 1990. Interaction of actin from pregnant and nonpregnant human uterus with the uterine myosin subfragment-1: actin activated ATPase activities and actin binding. Biochem. (Life Sci. Adv.) 9:71-77.

27. Ewoane, C., and F. Cavaille. 1990. ATPase activity of reconstituted actomyosin from pregnant and non-pregnant human uterus: its dependence on the actin isoforms. Biochem. (Life Sci. Adv.). 9:5-10.

28. Hartshorne, D. J., and A. Gorecka. 1980. The biochemistry of the contractile proteins of smooth muscle. Handb. Physiol. 11:93-120.

29. Rubenstein, P. A., and J. A. Spudich. 1977. Actin microheterogeneity in chick embryo fibroblasts. Proc. Natl. Acad. Sci. USA. 74:120-123.

30. Itoh, M., and D. J. Hartshorne. 1990. Phosphorylation of myosin as a regulatory mechanism in smooth muscle. Prog. Clin. Biol. Res. 327:57-72.

31. Sobue, K., K. Kanda, T. Tanaka, and N. Ueki. 1988. Caldesmon: a common actin-linked regulatory protein in the smooth muscle and nonmuscle contractile system. J. Cell. Biochem. 37:317-325.

32. Hemric, M. E., and J. M. Chalovich. 1988. Effect of caldesmon on the ATPase activity and the binding of smooth and skeletal muscle subfragments to actin. J. Biol. Chem. 263:1878-1885.

33. Ikebe, M., and S. Reardon. 1988. Binding of caldesmon to smooth muscle myosin. J. Biol. Chem. 263:3055-3058.

34. Winder, S. J., and M. P. Walsh. 1990. Smooth muscle calponin: inhibition of actomyosin MgATPase and regulation by phosphorylation. J. Biol. Chem. 265:10148-10155.

35. Cohen, P. 1989. The structure and regulation of protein phosphatases. Annu. Rev. Biochem. 58:453-508.

36. Chisholm, A. A. K., and P. Cohen. 1988. The myosin-bound form of protein phosphatase 1 (PP-1 $\left.1_{M}\right)$ is the enzyme that dephosphorylates native myosin in skeletal and cardiac muscles. Biochim. Biophys. Acta. 971:163-169.

37. Haeberle, J. R., D. R. Hathaway, and A. A. DePaoli-Roach. 1985. Dephosphorylation of myosin by the catalytic subunit of a type- 2 phosphatase produces relaxation of chemically skinned uterine smooth muscle. J. Biol. Chem. 260:9965-9968.

38. Pato, M. D., and E. Kerc. 1985. Purification and characterization of a smooth muscle myosin phosphatase from turkey gizzards. J. Biol. Chem. 260:12359-12366.

39. Hoar, P. E., M. D. Pato, and W. G. L. Kerrick. 1985. Myosin light chain phosphatase: effect on the activation and relaxation of gizzard smooth muscle skinned fibers. J. Biol. Chem. 260:8760-8764.

40. Pato, M. D., and E. Kerc. 1990. Comparison of the properties of the protein phosphatases from avian and mammalian smooth muscles: purification and characterization of rabbit uterine smooth muscle phosphatases. Arch. Biochem. Biophys. 276:116-124.
41. Bialojan, C., J. C. Rüegg, and J. DiSalvo. 1985. Phosphatase-mediated modulation of actin-myosin interaction in bovine aoric actomyosin and skinned porcine carotid artery. Proc. Soc. Exp. Biol. Med. 178:36-45.

42. Takai, A., M. Troschka, G. Mieskes, and A. V. Somlyo. 1989. Protein phosphatase composition in the smooth muscle of guinea pig ileum studied with okadaic acid and inhibitor 2. Biochem. J. 262:617-623.

43. Ishihara, H., H. Ozaki, K. Sato, M. Hori, H. Karaki, S. Watabe, Y. Kato, N. Fusetani, K. Hashimoto, D. Uemura, and D. J. Hartshorne. 1989. Calciumindependent activation of contractile apparatus in smooth muscle by calyculinA. J. Pharmacol. Exp. Ther. 250:388-396.

44. Adelstein, R. S., M. A. Conti, D. R. Hathaway, and C. B. Klee. 1978. Phosphorylation of smooth muscle myosin light chain kinase by the catalytic subunit of adenosine $3^{\prime}: 5^{\prime}$-monophosphate-dependent protein kinase. J. Biol. Chem. 253:8347-8350.

45. Ikebe, M., M. Inagaki, K. Kanamura, and H. Hidaka. 1985. Phosphorylation of smooth muscle myosin light chain kinase by $\mathrm{Ca}^{2+}$-activated, phospholipid-dependent protein kinase. J. Biol. Chem. 260:4547-4550.

46. Nishikawa, M., S. Shirakawa, and R. S. Adelstein. 1985. Phosphorylation of smooth muscle myosin light chain kinase by protein kinase $\mathrm{C}$ : comparative study of the phosphorylated sites. J. Biol. Chem. 260:8978-8983.

47. Hashimoto, Y., and T. R. Soderling. 1990. Phosphorylation of smooth muscle myosin light chain kinase by $\mathrm{Ca}^{2+} /$ calmodulin-dependent protein kinaseII: comparative study of the phosphorylation sites. Arch. Biochem. Biophys. 278:41-45.

48. Stull, J. T., L.-C. Hsu, M. G. Tansey, and K. E. Kamm. 1990. Myosin light chain kinase phosphorylation in tracheal smooth muscle. J. Biol. Chem. 265:16683-16690.

49. Tansey, M. G., R. A. Word, H. Hidaka, H. A. Singer, C. M. Schworer K. E. Kamm, and J. T. Stull. 1992. Phosphorylation of myosin light chain kinase by the multifunctional calmodulin-dependent protein kinase II in smooth muscle cells. J. Biol. Chem. 267:12511-12516.

50. Moody, C., W. Lehman, and R. Craig. 1990. Caldesmon and the structure of smooth muscle thin filaments: electron microscopy of isolated thin filaments. J. Muscle Cell. Motil. 11:176-185.

51. Katsuyama, H., C.-L., A. Wang, and K. G. Morgan. 1992. Regulation of vascular smooth muscle tone by caldesmon. J. Biol. Chem. 267:14555-14558.

52. Ishikawa, R., O. Kagami, C. Hayashi, and K. Kohama. 1992. The binding of nonmuscule caldesmon from brain to microtubules: regulation by $\mathrm{Ca}^{2+} / \mathrm{cal}-$ modulin and cdc2 kinase. FEBS (Fed. Eur. Biochem. Soc.) Lett. 299:54-56.

53. Yamashiro, S., and F. Matsumura. 1991. Mitosis-specific phosphorylation of caldesmon: possible molecular mechanism of cell rounding during mitosis. Bioessays. 13:563-568.

54. Marston, S. B., and C. S. Redwood. 1992. Inhibition of actin-tropomyosin activation of myosin MgATPase activity by the smooth muscle regulatory protein caldesmon. J. Biol. Chem. 267:16796-16800.

55. Pinter, K., and S. B. Marston. 1992. Phosphorylation of vascular smooth muscle caldesmon by endogenous kinase. FEBS (Fed. Eur. Biochem. Soc.) Lett. 305:192-196

56. Galulla, G. 1977. A morphological study of the mechanical coupling between smooth muscle cells. In Excitation-Contraction Coupling in Smooth Muscle. R. Casteels, T. Godfraind, and J. C. Rüegg, editors. Elsevier/North-Holland, Amsterdam. 3-12.

57. Izumi, H., J. Ichihara, Y. Uchiumi, and K. Shirakawa. 1990. Gestationa changes in mechanical properties of skinned muscle tissue of human myometrium. Am. J. Obstet. Gynecol. 163:638-647.

58. Murphy, R. A. 1979. Filament organization and contractile function in vertebrate smooth muscle. Annu. Rev. Physiol. 41:737-748. 